\title{
Gastrointestinal evacuation of particulate matter in polar cod Boreogadus saida
}

\author{
Bjørn-Steinar Sæther ${ }^{1, *}$, Jørgen Schou Christiansen ${ }^{2}$, Malcolm Jobling ${ }^{1,2}$ \\ ${ }^{1}$ Norwegian College of Fishery Science, University of Tromse, 9037 Tromse, Norway \\ ${ }^{2}$ Norwegian Institute of Fisheries and Aquaculture, 9291 Tromsø, Norway
}

\begin{abstract}
Gastrointestinal evacuation of inert particles was monitored in the polar cod Boreogadus saida (Lepechin), held at a temperature of $0.5^{\circ} \mathrm{C}$. Fish ( $31.8 \mathrm{~g} \pm 0.8 \mathrm{SD}$ ) were fed a moist diet, based on natural prey items, containing a particulate marker. Evacuation of marker from the gastrointestinal tract started $48 \mathrm{~h}$ after ingestion of a meal. The average time needed to evacuate $50 \%$ of the marker was estimated to be $132 \mathrm{~h}$, whereas the total evacuation time was approximately $400 \mathrm{~h}$. This may indicate that the polar cod does not feed on a daily basis at temperatures close to zero because of the prolonged time needed to evacuate meals. This work provides a methodological basis for studies of feeding and growth in polar cod using $\mathrm{X}$-radiography.
\end{abstract}

KEY WORDS: Polar cod B Boreogadus saida Food intake - Gastrointestinal evacuation - Radiography

\section{INTRODUCTION}

The polar cod Boreogadus saida (Lepechin) is an abundant cryopelagic species with a wide distribution in the Arctic ocean. It constitutes a key link between lower trophic levels and top predators such as other fish species, birds, and marine mammals (Hobson \& Welch 1992). Knowledge of feeding and food evacuation rates in polar fish is scarce, and the central position of polar cod in the arctic food chain makes information about food turnover for this species of particular interest.

Evacuation rates of Pagothenia borchgrevinki, an Antarctic fish species with a similar ecological position to the polar cod, have been estimated using a sacrifice method (Montgomery et al. 1989), and this method has recently been used to study gastric evacuation rates in polar cod fed natural prey (Hop \& Tonn 1998). The initial meal size is rarely known when this method is used; additionally, large sample sizes are needed to obtain reliable results and evacuation of meals by individual fish cannot be tracked. Further, the method is destructive, precluding repeated use of individuals.

•E-mail: bjoerns@nfh.uit.no
We examined gastrointestinal evacuation rates of polar cod by feeding fish with food labelled with an inert particulate marker and following evacuation using X-radiography. The X-radiographic technique enables estimation of initial meal size, and permits repeated recording of the time course of evacuation at the individual level. Possible effects of handling and post-prandial feeding on evacuation were assessed.

\section{MATERIAL AND METHODS}

Individually tagged (FTF 69 fingerling tags, Floy ${ }^{\otimes}$ Tag \& Manufacturing Inc. Seattle, Washington, USA), adult polar cod were randomly distributed among 3 tanks, each tank containing 15 fish (mean weight $31.8 \mathrm{~g}$ [0.8 SD, $n=45]$ ) (Groups $A$ to C). Fish were then left to settle without food for $2 \mathrm{~d}$. The fish were held in full strength seawater at $0.5^{\circ} \mathrm{C}$, under continuous light conditions. At the start of the experiment the fish were hand fed a moist food formulation (Christiansen \& George 1995) containing inert X-ray dense marker (Ballotini lead glass beads; size 400 to $455 \mu \mathrm{m}$; Jencons Ltd., Leighton Buzzard). Ingestion and evacuation of the marker were monitored by X-radiography (Talbot \& Higgins 1983, Jobling et al. 1995). One hour after 
feeding, the fish were anaesthetised (benzocaine, $25 \mathrm{mg}$ $\mathrm{I}^{-1}$ for $5 \mathrm{~min}$ ) and radiographed (Siemens Nanodor 2, $12 \mathrm{mAs}, 50 \mathrm{kV}$ ). The X-ray films (Agfa Structurix D7) were developed and the number of marker particles in the gastrointestinal tract (GI-tract) of individual fish was counted. Samples of food were also X-radiographed, and the number of ballotini regressed against weight of food by simple linear regression (Talbot \& Higgins 1983, Wilkinson 1992):

$$
F=24+41 b
$$

where $F$ is the weight of food in $\mathrm{mg}$ and $b$ is the number of ballotini $\left(\mathrm{r}^{2}=0.982 ; F_{1,32}=1761.1 ; \mathrm{p}<0.001\right)$. The fish in Group A were radiographed sequentially at $0,48,120,168,264,336,408$ and $504 \mathrm{~h}$, and those in Groups B and C at 0, 168 and 408 h. Fish in Groups A and $B$ were offered additional meals to satiation twice a week, whereas fish in Group C were deprived of food following the initial meal. The food provided in the later meals was identical to that given in the initial meal, except that it lacked particulate marker. Uneaten food was removed from the tank 15 min after feeding, enabling an estimate of group food intake to be made 'by difference'. Following the termination of the evacuation study, the fish were again fed a meal of marked feed and intake was estimated. When comparisons were made of amounts consumed in the initial and final meals estimated 'by difference' and from the $X$-ray technique, food intake recorded 'by difference' was higher (mean difference $1.65 \mathrm{~g}_{\text {food fish }}^{-1} \mathrm{meal}^{-1}$ [SD 0.27]). Pairwise correlation of food intake recorded by the 2 different methods were close to being significant (Pearson; $r=0.784 ; n=6 ; p=0.067$ ). The discrepancy between food intake recorded by $X$-ray and 'by difference' may be due to the consistency of the formulated moist food; some food particles fragmented during ingestion, resulting in losses of food, thus leading to an overestimation of group food intake when using the 'by difference' method. Nevertheless, consumption estimated 'by difference' was considered a useful indicator of general trends in intake.

A Kolmogarov-Smirnov test, as modified by Lilliefors, was used to test the data for deviation from a normal distribution, and homogeneity of variance was assessed by visual inspection of data. Possible differences in fish body weights and food intake between groups were tested using an ANOVA (Wilkinson 1992). A Pearson correlation analysis was used to assess interaction between individual food intake and body weight (Wilkinson 1992). The evacuation of marker was described by iterative fitting of non-linear least square curve (Elashoff et al. 1982). For fish in Group A evacuation curves were plotted for individual fish, and the half time of evacuation of marker (T50\%) was calculated for each individual. One fish was excluded due to few observations $(n=2)$ before complete evacuation; the remaining 13 fish all had an coefficient of determination $\left(r^{2}\right)$ of 0.936 or higher, and standard residuals homogeneously distributed around 0 through time. The relationship between T50\% and initial food intake was examined using a linear regression analysis (Wilkinson 1992).

\section{RESULTS}

The distribution of fish body weights, but not evacuation of marker data, fulfilled the assumptions for parametric analyses (Kleinbaum et al. 1988); thus, results on gastrointestinal content of marker are presented as medians with $95 \%$ CI (Zar 1984). One fish in Group A died on Day 5 and data from this individual were excluded from analyses. There were no significant differences in initial body weights between the experimental groups $\left(F_{2,41}=0.057, \mathrm{p}=0.945\right)$. Initial food intake did not differ significantly between groups (Fig. $1 ; F_{2,40}=1.456 ; \mathrm{p}=0.245 ;$ fish body weight as covariable $\left.\left[F_{1,40}=5.585 ; \mathrm{p}=0.023\right]\right) ;$ median food intake $(95 \% \mathrm{CI})$ Group A. $0.8(0.6$ to 1.4$), \mathrm{B} 1.0(0.7$ to 1.7), C $1.3(0.7$ to 2.4$) \mathrm{g}$ food fish $^{-1}$ meal $^{-1}$. There was a positive correlation between food intake and fish body weight in Group A (Pearson $r=0.566, \mathrm{n}=14, \mathrm{p}=$ $0.035)$, but not in Group B $(r=0.461, \mathrm{n}=15, \mathrm{p}=0.084)$ or $C(r=0.211, n=15, p=0.451)$, although there was a tendency for the largest fish to consume most food.

Fish in Group A evacuated few marker particles from the Gl-tract during the first $48 \mathrm{~h}$, indicating a minimum passage time of marker through the GI-tract of approx-

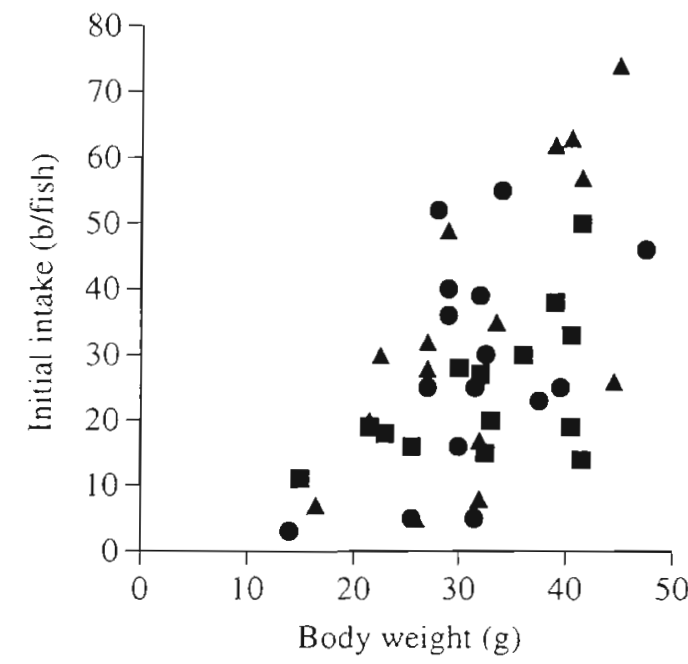

Fig. 1. Number of marker particles (b) consumed in the initial meal ingested by polar cod held at $0.5^{\circ} \mathrm{C}$. Symbols: Group A

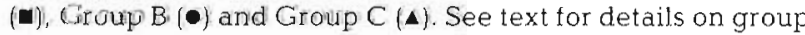
treatments 


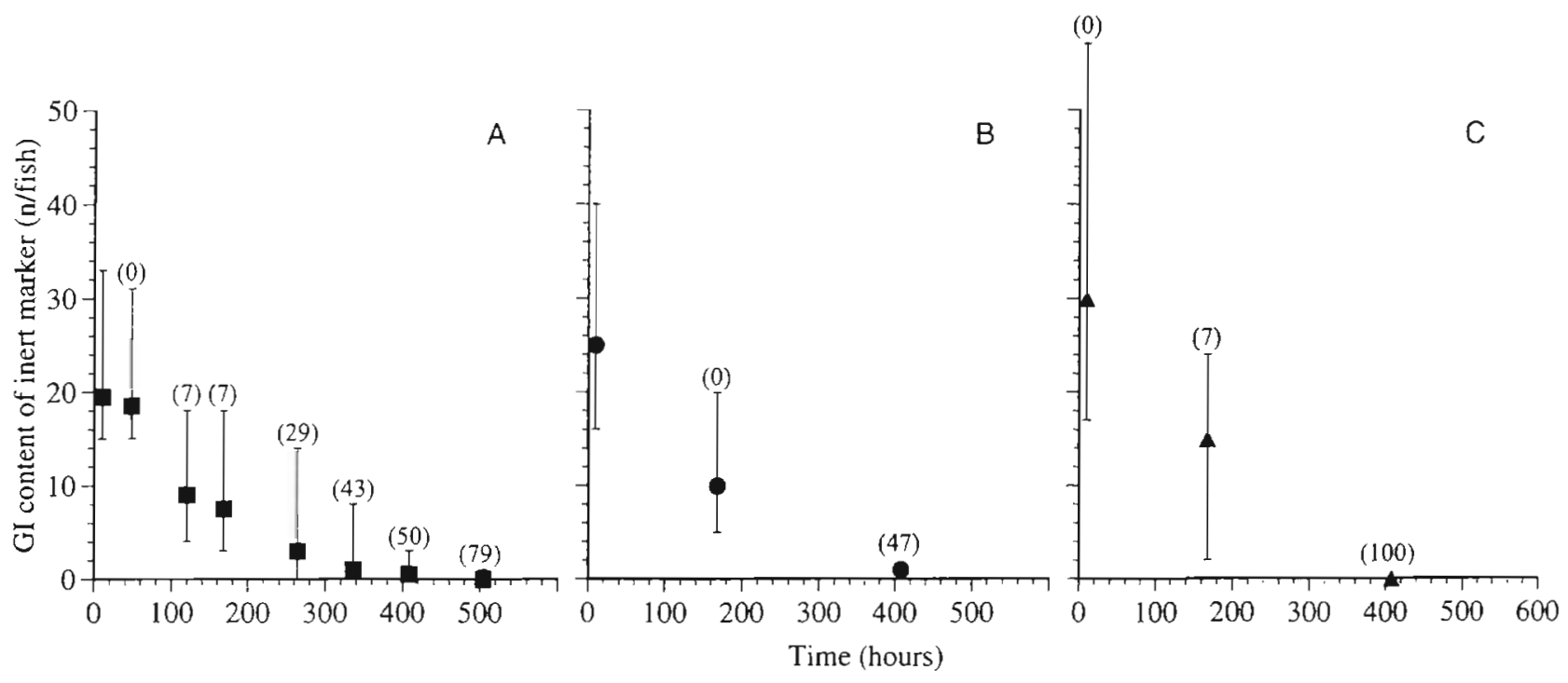

Fig. 2. Gastrointestinal (GI) evacuation of inert marker in polar cod kept at $0.5^{\circ} \mathrm{C}$. Data are given as medians and variation is indicated by $95 \%$ confidence intervals. Numbers in parentheses denote the percent of fish devoid of marker. (A) Repeatedly fed, frequently handled fish, (B) repeatedly fed, less frequently handled fish, and (C) food-deprived fish handled as in B

imately $2 \mathrm{~d}$ (Fig. 2A). After this initial delay, evacuation of marker could be described by the least square exponential equation:

$$
b=27.89 \mathrm{e}^{(-0.009 X)}
$$

where $b$ is the number of marker particles and $X$ is time within the range 48 to $408 \mathrm{~h}$ after the initial meal $\left(F_{2,4}=\right.$ $457.4 ; \mathrm{p}<0.01$ ). The fitted curve had a coefficient of determination $\left(\mathrm{r}^{2}\right)$ of 0.991 , with residuals homogeneously distributed around 0 . There were no differences among groups in numbers of marker remaining after $168 \mathrm{~h}$, and fish in all groups had reduced the median marker numbers to 0 within $408 \mathrm{~h}$ (Fig. 2). However, only fish in Group C (deprived of food after the initial meal) were completely devoid of marker at this time (Fig. 2). When the amounts of food consumed by fish in Groups A and $B$ after the initial meal were compared, the fish in Group B were found to have consumed $0.44 \mathrm{~g} \mathrm{fish}^{-1}$ meal $^{-1}$ more than those in Group A $(95 \%$ CI 0.04 to $0.84 \mathrm{~g} \mathrm{fish}^{-1} \mathrm{meal}^{-1}$ ). This indicates that the frequent handling to which fish in Group A were subjected resulted in a reduction in subsequent food intake.

The time for individual fish to evacuate $50 \%$ of the ingested marker (T50\%) was estimated for Group A (Fig. 3); average T50\% was calculated to be $132 \mathrm{~h}$, but $\mathrm{T} 50 \%$ was significantly correlated with numbers of ingested marker. The linear relationship (based on a least square stepwise backwards regression procedure; fish body weight and [weight $\times$ number of marker] excluded from the model at $\mathrm{p}=0.15$ ) was described by:

$$
\mathrm{T} 50 \%=46.9+3.09 b
$$

where $b$ is the initial number of marker $\left(\mathrm{r}^{2}=0.587\right.$; $F_{1,11}=15.6 ; \mathrm{p}<0.01 ; 1$ outlier excluded). In addition, any confounding effect of fish body weight was considered and found to be negligible (Kleinbaum et al. 1988). The positive slope of the regression (3.09) demonstrates that evacuation time increases with increasing meal size, and the intercept $(46.9 \mathrm{~h})$ corresponds closely to the observed initial delay time for evacuation ( $48 \mathrm{~h})$.

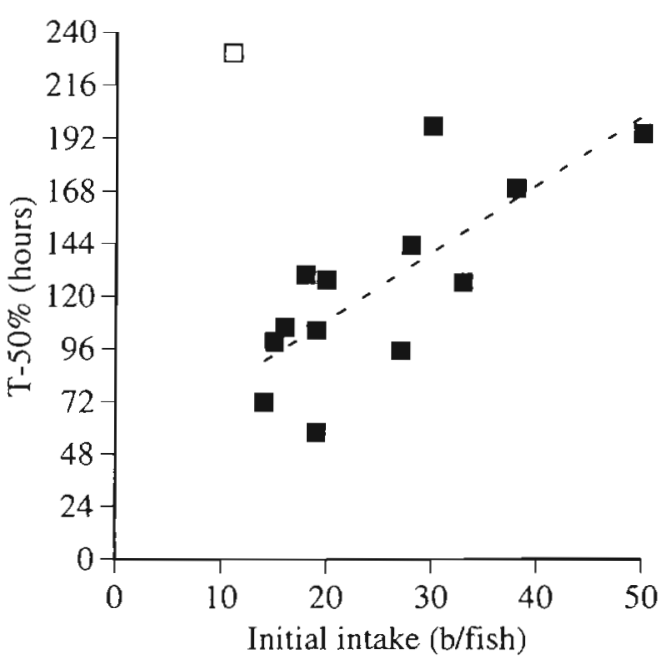

Fig. 3. Time required for polar cod to evacuate $50 \%$ of inert particles from the GI-tract. The open square indicates an outlier that is not included in the statistical analyses. The line was fitted using linear regression analysis 


\section{DISCUSSION}

The passage of inert particles through the Gl tract of polar cod occurs slowly at $0.5^{\circ} \mathrm{C}$, the median evacuation time being approximately $400 \mathrm{~h}$. This is similar to the findings of Hop \& Tonn (1998), who reported that gastric evacuation required 12 to $13 \mathrm{~d}$ in polar cod held at a slightly lower temperature. Since return of appetite may be inversely correlated to gastric emptying (Grove et al. 1978), a long evacuation time may imply that food intake and growth in this species are limited by low GI evacuation rates when food is abundant (Hop et al. 1997). Such a long GI evacuation time implies that specific dynamic action (SDA) may elevate metabolism above the fasting rate for several days after ingestion of a meal (c.f. Saunders 1963). This should be taken into account when metabolic rate studies are performed on this species.

Evacuation of marker from the gut commenced after an initial delay of about $48 \mathrm{~h}$ (Fig. 2A), this delay representing the minimum time needed to transport the marker through the system. Following this initial delay, the evacuation appeared to be exponential, with a relatively rapid evacuation of marker during the first 4 to $5 \mathrm{~d}$. The general pattern resembles that recorded for gastric evacuation in the rainbow trout Oncorhynchus mykiss (Grove et al. 1978) the Atlantic cod Gadus morhua (dos Santos \& Jobling 1991a), and GI evacuation in the turbot Psetta maxima (Sæther \& Jobling 1997). A similar pattern can also be implied from results of studies on polar cod fed natural prey (Hop \& Tonn 1998). Polar cod in the present experiment required about $130 \mathrm{~h}$ to evacuate $50 \%$ of the inert matter from the gut following ingestion of a meal of $0.8 \mathrm{~g}$ food fish $^{-1}$ meal $^{-1}$ (Fig. 2A), but the time needed to empty half of the meal increased with increasing meal size (Fig. 3). Hop \& Tonn (1998) reported a half time for gastric evacuation of approximately $150 \mathrm{~h}$ for polar cod $\left(21.1 \mathrm{~g}\right.$ body weight) held at $-0.49^{\circ} \mathrm{C}$; fish had consumed a single meal of natural prey (Calanus sp. and Themisto sp.) of approximately $2 \mathrm{~g}$ food fish ${ }^{-1}$ $(9.25 \%$ of $\mathrm{W})$. There is little information about GI evacuation of coldwater fish species, but long evacuation times seem typical, with several days being needed to empty the stomach after ingestion of a meal (Pagothenia borchgrevinki [Montgomery et al. 1989], Theragra chalcogramma [Smith et al. 1989], G. morhua [dos Santos \& Jobling 1991a], Lota lota [Pääkkönen \& Marjomäki 1997], Boreogadus saida [Hop \& Tonn 1998]). Polar cod seem to have GI evacuation times that are longer than those reported for other coldwater species, although direct comparison is difficult because of differences in experimental protocols, food types and holding temperatures used in the various studies.

The time required to evacuate the gut increased with increasing meal size (Fig. 3), but the relationship be- tween ingestion and T50\% indicates that a doubling of food intake did not lead to a doubling of evacuation time. This is concordant with reports that GI evacuation is dependent on meal size, with higher evacuation rates as meal size increases (Jobling 1995, Pääkkönen \& Marjomäki 1997, Sæther \& Jobling 1997). Handling associated with repeated X-raying of fish resulted in a reduction in food intake, and this should be taken into account when consecutive food intake measurements are to be made. However, repeated handling was not found to significantly influence GI evacuation, as also reported in turbot Psetta maxima (Sæether \& Jobling 1997). Repeated feeding did not seem to affect evacuation markedly, but as only the fish deprived of food after the initial meal were devoid of marker at the termination of the experiment, this might indicate that repeated feeding leads to some prolongation of the time needed to completely evacuate inert material from the GI-tract. dos Santos \& Jobling (1991b) reported that when Atlantic cod Gadus morhua were fed at regular intervals there was a preferential retention of particulate marker in the stomach, and a similar response was described in turbot by Grove (1986). By contrast, Talbot et al. (1984) reported increased gastrointestinal evacuation of particulate marker in the salmon Salmo salar under conditions of repeated feeding.

The results of this study show that the X-ray method can be used to assess food intake in polar cod held at low temperatures $\left(0.5^{\circ} \mathrm{C}\right)$, provided fish are X-rayed within $48 \mathrm{~h}$ after ingestion of a meal. Frequent handling of this species seems to reduce food intake. The discrepancy between food intake recorded 'by difference' and food intake measured by radiography implies that the former method is inadequate for accurate quantification of food intake, at least when using wet or moist formulated food. When using the X-ray method, a minimum of 400 h should be allowed to elapse between consecutive food intake measurements on polar cod held at low temperatures, because marker remaining from a previous meal would lead to overestimation of food intake. The results of the present study add to the evidence that $X$-radiography may be a valuable experimental tool to assess food intake-growth relationships in captive key species from natural populations, provided that some simple precautions are taken.

Acknowledgements. This study forms part of project no: 108096/122 supported by the Norwegian Research Council.

\section{LITERATURE CITED}

Christiansen JS, George SG (1995) Contamination of food by crude oil affects food selection and growth performance, but not appetite, in an Arctic fish, the polar cod (Boreogadus saida). Polar Biol 15:277-281

dos Santos J, Jobling M (1991a) Factors affecting gastric 
evacuation in cod, Gadus morhua L., fed single-meals of natural prey. J Fish Biol 38:697-713

dos Santos J, Jobling M (1991b) Gastric emptying in cod Gadus morhua L.. emptying and retention of indigestible solids. J Fish Biol 38:187-197

Elashoff JD, Reedy TJ, Meyer JH (1982) Analysis of gastric emptying data. Gastroenterology 83:1306-1312

Grove DJ (1986) Gastro-intestinal physiology: rates of food processing in fish. In: Nilsson S, Holmgren S (eds) Fish physiology - recent advances. Croom Helm, Beckenham, Kent, p 140-152

Grove DJ, Loizides L, Nott J (1978) Satiation amount, frequency of feeding and gastric emptying rate in Salmo gairdneri. J Fish Biol 14:229-238

Hobson KA, Welch HE (1992) Determination of trophic relationships within a high Arctic marine food web using $\partial^{13}$ and $\partial^{15} \mathrm{~N}$ analysis. Mar Ecol Prog Ser 84:9-18

Hop $\mathrm{H}_{1}$ Tonn WM (1998) Gastric evacuation rates and daily rations of Arctic cod (Boreogadus saida) at low temperatures. Polar Biol 19:293-301

Hop $H_{1}$ Tonn WH, Welch HE (1997) Bioenergetics of Arctic cod (Boreogadus saida) at low temperatures. Can J Fish Aquat Sci 54:1772-1784

Jobling M (1995) Environmental biology of fishes. Chapman \& Hall, London

Jobling $M$, Arnesen AM, Baardvik BM, Christiansen JS, Jørgensen EH (1995) Monitoring voluntary feed intake under practical conditions, methods and applications. J Appl Ichthyol 11:248-262

Editorial responsibility: Otto Kinne (Editor), Oldendorf/Luhe, Germany
Kleinbaum DG, Kupper LL, Muller KE (1988) Applied regression analysis and other multivariable methods, 2 nd edn. Duxbury Press, Belmont, CA

Montgomery JC, Foster BA, Cargill JM (1989) Stomach evacuation rate in the planktivorous Antarctic fish Pagothenia borchgrevinki. Polar Biol 9:405-408

Pääkkönen JPJ, Marjomäki TJ (1997) Gastric evacuation rate of burbot fed single-fish meals at different temperatures. J Fish Biol 50:555-563

Saunders RL (1963) Respiration of the Atlantic cod. J Fish Res Board Can 20:373-386

Smith RL, Paul JM, Paul AJ (1989) Gastric evacuation in walleye pollock, Theragra chalcogramma. Can J Fish Aquat Sci 46:489-493

Sæther BS, Jobling M (1997) Gastrointestinal evacuation of inert particles by turbot, Psetta maxima: evaluation of the $\mathrm{X}$-ray method for use in feed intake studies. Aquat Living Resour 10:359-364

Talbot C, Higgins PJ (1983) A radiographic method for feeding studies on fish using metallic iron powder as a marker. J Fish Biol 23:211-220

Talbot C, Higgins PJ, Shanks AM (1984) Effects of pre- and post-prandial starvation on meal size and evacuation rate of juvenile Atlantic salmon, Salmo salar L. J Fish Biol 25: $551-560$

Wilkinson L (1992) SYSTAT: The system for statistics. SYSTAT, Inc, Evanston, IL

Zar JH (1984) Biostatistical analysis, 2nd edn. Prentice Hall Inc, Englewood Cliffs, New Jersey

Submitted: December 23, 1998; Accepted: June 3, 1999

Proofs received from author(s): October 14, 1999 